\title{
Effect of Nitrogen Level on Trace Elements of Allium fistulosum L.
}

\author{
Lin Zhou ${ }^{1}$, Qiulin Yue ${ }^{1 *}$, Rongzong Cui ${ }^{2}$, Lin Zhao ${ }^{1}$, Lingxia Xu ${ }^{1}$, Xinli Liu ${ }^{1}$ \\ 1 Shandong Provincial Key Lab. of Microbial Engineering, Qi Lu University of Technology \\ (Shandong Academy of Sciences), Jinan 250353, P.R. China \\ 2 Institute of Agricultural Resources and Environment, Shandong Academy of Agricultural \\ Sciences, Jinan 250100, P.R. China \\ *Correspondence: yueqiulin88@163.com; Tel \& fax: +86 53189631776
}

Keywords: Allium fistulosum L.; trace elements; ICP-MS; nitrogen

Abstract. In this paper, the polytetrafluoroethylene tank high pressure digestion method was used for the determination of trace elements of Allium fistulosum L.by ICP-MS. Welsh onion cultivars 'Zhangqiu' were selected as the experimental materials. The influence of different nitrogen lever on the content of trace elements in different parts of Allium fistulosum L.were investigated. The results showed that the contents of $\mathrm{Ca}, \mathrm{Mn}, \mathrm{Cu}$ and $\mathrm{Zn}$ in the leaves were higher than those in the stem. The content of $\mathrm{Fe}$ in the stem was much larger than that in the leaves. Under the condition of nitrogen fertilizer, the content of trace elements in the Welsh onion decreased with the increasing of nitrogen level.

\section{Introduction}

Scallions are not only well-known as a common spice seasoning, but also they contain rich nutrition such as amino acids, protein, pyruvate, vitamin $\mathrm{C}$ and trace element, which make it has the effect of detoxification ,condiment, antimicrobial and diastolic blood vessels ${ }^{[1,3]}$. The trace elements in green onions participate in the synthesis of hormones, enzymes, vitamins and other macromolecules in the human body, which play a certain role in regulating the growth and health of the human body ${ }^{[1]}$. Nitrogen as the necessary element for plant growth, is an important element of protein, pith, nucleic acid, organic nitrides which is the basic substances in the cytoplasm, nucleus and biofilm, so it was called the element of life ${ }^{[2]}$. Nitrogen had a significant effect on the quality of green onions.

At present, there have been many researches on the fertilization of green onions. Most of the reports focused on different fertilizer varieties, potash fertilizer and organic-inorganic fertilizers in order to improve the yield and economic benefits of scallion ${ }^{[4,6]}$. However, there were few of the systematic study on the effects of nitrogen on the trace elements of scallion. To this end, in this study, in order to provide a basis for the growth and scientific fertilization of green onions, Zhangqiu scallion was taken as the research object to explore the effect of different levels of nitrogen on the trace elements in green onions and know the content of trace elements in different parts of onion to provide reference data for further using the edible value of different parts of onions ${ }^{[5]}$. In this study, the contents and changes of trace elements in different parts of onion under different nitrogen levels were determined by ICP-MS.

\section{Materials and methods}

Materials. The test was carried out for three different conditions including nitrogen-free fertilizer, total nitrogen fertilizer and nitrogen fertilizer halved in the experimental dwarf area of Zhangqiu, each of conditions was processed in three parallel. In accordance with the nutrient requirements in the bearing stage of scallion, Nitrogen fertilizer was divided into 3-4 times to add. The samples of Onion were collected for testing in the Harvest (November 13th) ${ }^{[1]}$.

Sample processing methods. 5 green onions were collected randomly at each treatment condition. After washing and draining, the stems and leaves were separated and placed in the dry blast box at 105 ${ }^{\circ} \mathrm{C}$ for $15 \mathrm{~min}$. Then they were dried to constant weight at $70{ }^{\circ} \mathrm{C}^{[7]}$. 
PTFE tank high pressure digestion method ${ }^{[8]}$ : $0.2 \mathrm{~g}$ dry samples was placed in PTEE tank which 3 $\mathrm{mL}$ nitric acid was added in advance. Then the tank was placed in $40{ }^{\circ} \mathrm{C}$ pre-digestion oven overnight. After cooled to room temperature, the tank was added $2 \mathrm{~mL} \mathrm{H}_{2} \mathrm{O}_{2}$ in with the lid tighten and heated at $50{ }^{\circ} \mathrm{C}$ for $1 \mathrm{~h}$. The temperature was gradually raised to $160{ }^{\circ} \mathrm{C}$ for $4 \mathrm{~h}$. After cooling down, the digestion solution was transferred to $50 \mathrm{~mL}$ volumetric flask, in addition to the above steps, a blank was made. In the process of sample determination, the blank solution and sample solution were measured one by one. Before each injection, flushing the tubing for 30 seconds. If the measured element content is greater than the highest point of the standard curve, it should be diluted after being tested. If the content of the measured element is greater than the highest point of the standard curve, it should be diluted.

Correction of matrix effects and interface effects. Selecting $\mathrm{Ge}, \mathrm{Sc}$, In and $\mathrm{Bi}$ as internal standard elements, these elements content is very low or not existed in the sample. The mass and the ionization energy are basically close to the measured elements, which can eliminate matrix effect and interface effect, and effectively regulate signal drift $^{[9,10]}$.

Linear ranges and detection limit of determination elements ${ }^{[11]}$. The reagent solutions during whole process was measured parallelly 11 times, with 3 times the standard deviation divided by the slope of the corresponding elemental standard curve to calculate detection limit.

\section{Result analysis and discussion}

Linear ranges and detection limit of determination elements. By measuring the blank and standard curve, the linear range and detection limit of each element were measured by ICP-MS in table 1 .

Table 1 Linear ranges and detection limit of $\mathrm{Ca}, \mathrm{Mn}, \mathrm{Fe}, \mathrm{Cu}, \mathrm{Zn}$ elements

\begin{tabular}{cccc}
\hline Element & Linear regression equation & Correlation coefficient $\left(\mathrm{R}^{2}\right)$ & Detection limit $(\mu \mathrm{g} / \mathrm{ml})$ \\
\hline $\mathrm{Ca}$ & $\mathrm{y}=3.499 \mathrm{x}+4.678$ & 0.995 & 0.1337 \\
$\mathrm{Mn}$ & $\mathrm{y}=3.955 \mathrm{x}+5.675$ & 0.998 & 0.0014 \\
$\mathrm{Fe}$ & $\mathrm{y}=3.262 \mathrm{x}+9.177$ & 0.998 & 0.2814 \\
$\mathrm{Cu}$ & $\mathrm{y}=2.581 \mathrm{x}+3.373$ & 0.999 & 0.0013 \\
$\mathrm{Zn}$ & $\mathrm{y}=6.142 \mathrm{x}+8.307$ & 0.996 & 0.0135 \\
\hline
\end{tabular}

Sample data analysis. The results of ICP-MS showed that Zhangqiu green onions are rich in $\mathrm{Ca}$, $\mathrm{Mn}, \mathrm{Fe}, \mathrm{Cu}, \mathrm{Zn}$ elements. From the table 2. $\mathrm{Ca}, \mathrm{Mn}, \mathrm{Cu}$ green, $\mathrm{Zn}$ content was higher in leaves than that in the content of stems.

Table 2 The content of trace elements under different nitrogen level

\begin{tabular}{clccccc}
\hline Nitrogen level & Different parts & $\mathrm{Ca}(\mu \mathrm{g} / \mathrm{g})$ & $\mathrm{Mn}(\mu \mathrm{g} / \mathrm{g})$ & $\mathrm{Fe}(\mu \mathrm{g} / \mathrm{g})$ & $\mathrm{Cu}(\mu \mathrm{g} / \mathrm{g})$ & $\mathrm{Zn}(\mu \mathrm{g} / \mathrm{g})$ \\
\hline \multirow{2}{*}{ free nitrogen } & Leaves & 1.672 & 32.875 & 0.648 & 50.625 & 30.95 \\
& Stems & 0.296 & 10.712 & 262.225 & 6.27 & 26.90 \\
\multirow{5}{*}{ half nitrogen } & Leaves & 0.862 & 24.917 & 1.231 & 9.673 & 14.015 \\
& Stems & 0.787 & 12.97 & 135.225 & 3.842 & 17.232 \\
total nitrogen & Leaves & 2.181 & 9.047 & 57.22 & 2.70 & 12.08 \\
& Stems & 0.375 & 6.065 & 116.075 & 2.188 & 10.87 \\
\hline
\end{tabular}


From the Fig. 1, with the application of nitrogen levels increased, the content of $\mathrm{Ca}, \mathrm{Mn}, \mathrm{Cu}, \mathrm{Zn}$ was decreased in the leaves. From the Fig. 2, the content of trace elements Fe was also decreased in the stems. From the whole, the total amount of trace elements was significantly reduced.

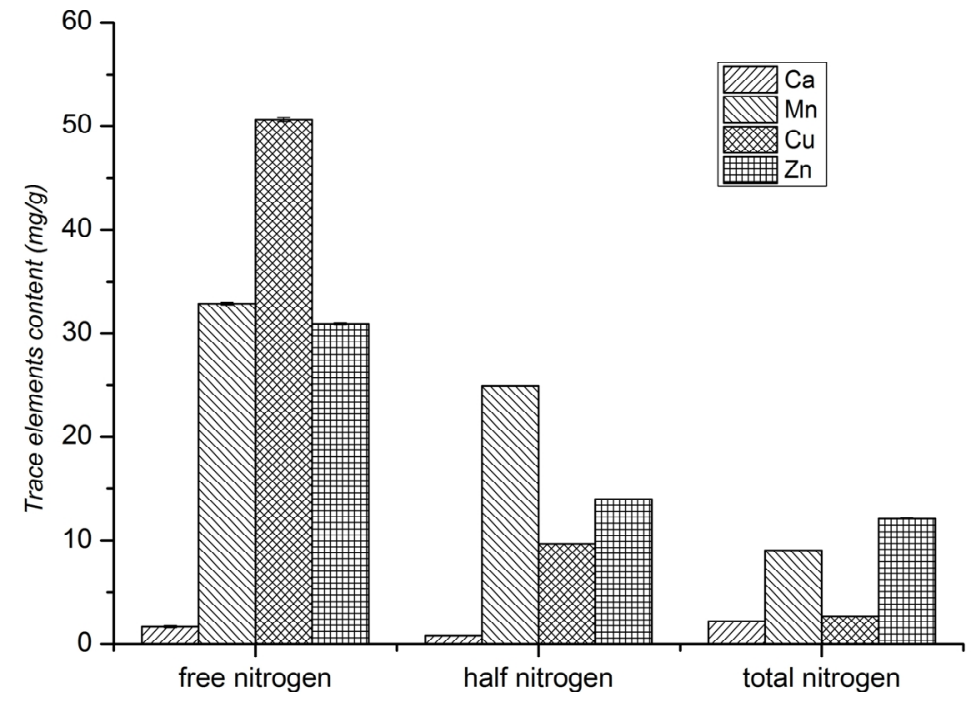

Fig. 1 Changes of $\mathrm{Ca}, \mathrm{Mn}, \mathrm{Cu}, \mathrm{Zn}$ elements under different nitrogen levels in the leaves

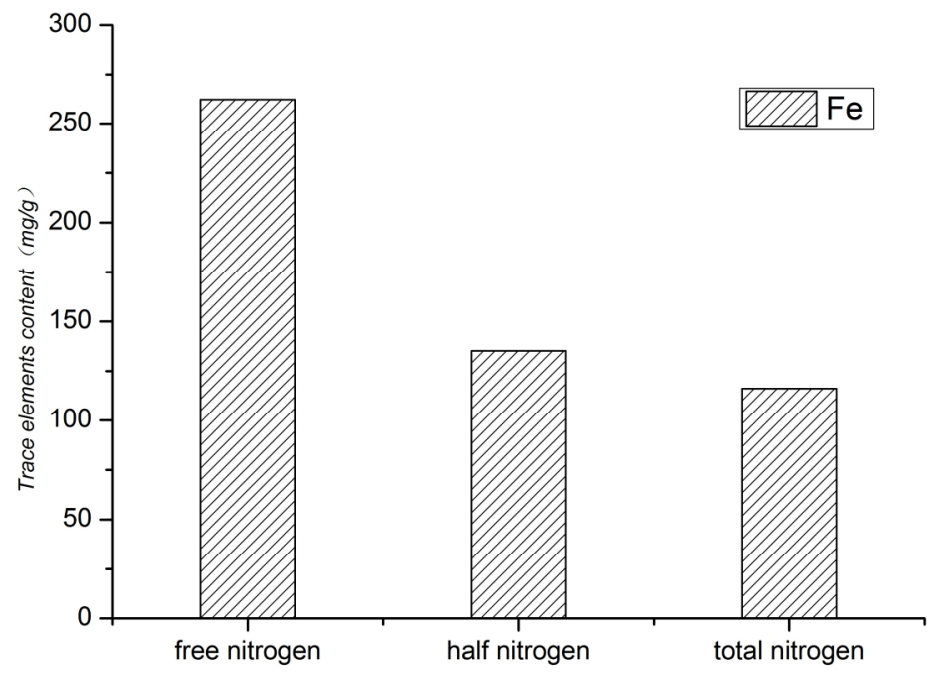

Fig. 2 Changes of Fe elements under different nitrogen levels in the stem

\section{Conclusions}

The contents of $\mathrm{Ca}, \mathrm{Mn}, \mathrm{Cu}$ and $\mathrm{Zn}$ in the leaves were greater than those in the stem under different levels of nitrogen. The content of trace elements in the was higher than that in the scallion. But with the increase of nitrogen level increased, the content of trace elements decreases in the Allium fistulosum L.

\section{Acknowledgements}

This work was financially supported by National Key R\&D Program of China (No. 2016YFD0200100).

\section{References}

[1] Shan Cheng-wei. High-yield and high-efficiency planting of Welsh Onion and its nutritional value [J]. Jilin Vegetables, 2013 (3): 24-25. 
[2] Cai D, Jianming L I, Fan X, et al. Effect of nitrogen, phosphorus and potassium supplementation on nutrient uptake,yield and quality of tomato in substrate culture[J]. Journal of Northeast Agricultural University, 2017.

[3] Zhang Yuzhi. Trace elements and human health [J]. Trace Elements and Health Research, 2004 (3): $56-58$

[4] Yao Wen-ju, ZENG Gui-lan. Preliminary Report on Fertilizer Efficiency of Organic and Inorganic Dual Fertilizer on Zhangqiu Scallion [J]. Shaanxi Agricultural Sciences, 2010, 56 (3): 79-79.[4]

[5] Guo Mao-Xia, TANG Si-Qun, LIU Xue-Mei, et al.Determination of Trace Elements of Zinc, Iron, Copper and Manganese in Onion Leaves and Scallions [J] .Food Sciences, 2014 (2): 22-24.

[6] Yang Guo, Cui Rongzong, Li Yan, et al.Effects of different amounts of potassium on yield and economic benefits of scallion [J]. Anhui Agricultural Sciences, 2008, 36 (25): 11000-11001.

[7] Kong Lingjun. Nitrogen and sulfur on the growth, yield and quality of the formation ofphysiological [D]. Shandong Agricultural University, 2013.

[8] Ouyang pei pei, Wu Huigang, Sun Zhidong, et al. Determination of trace elements in dried beans by pressure tank digestion and ICP-MS [J]. Chinese Journal of Health Laboratory Technology, 2013 (4): 833-835.

[9] Zhang Guang yi.Determination of Trace Elements in Welsh Onion by Microwave DigestionICP-MS [J] .Journal of Guangzhou Chemical Industry, 2016, 41 (4): 68-70.

[10] ZHANG Ying, XIA Yu-Lin, YANG Yi, et al.Study on determination of five heavy metal elements in liquor by on-line ICP-MS [J] .Brief Information of China Brew, 2011, 30 (4): 169-170.

[11] ZHAO Xiao-zhang, ZHANG Lin-lin, ZHANG Jian-ping, et al. Mass spectrum interference and elimination of ICP-MS in environmental analysis[J] .Chinese Environmental Monitoring, 2014, (3).

[12] WANG Zheng-Fan.Determination of Trace Elements in Different Parts of Welsh Onion [J] .Chinese Condiment, 2015 (1): 100-101.

[13] LIU Ya-xuan, LI Xiao-jing, BAI Jin-feng, et al.Sample pretreatment and determination of inorganic elements in plant samples [J]. Rock and Mineral Analysis, 2013, 32 (5): 681-693.

[14] QIAO Ai-xiang, CAO Lei, JIANG Ye, et al.Determination of 22 Major and Minor Elements in Plant Samples by Inductively Coupled Plasma-Atomic Emission Spectrometry with Dry Ashing and Microwave Digestion [J]. Rock and Mineral Analysis, 2010, 29 (1): 29.

[15] Zhu Xianjin, Yu Wantai, Ma Qiang, et al.Study on Contents and Distribution of TraceElementsin Crops Harvested with Different Fertilization Modes[J]. Chinese Journal of Eco-Agriculture, 2009, 17 (6): 1063-1068. 